\title{
EXAMINING INTERVENTION EFFECTIVENESS AND EFFICIENCY OUTCOMES IN SINGLE-CASE DESIGN STUDIES
}

\author{
Julie Q. Morrison \\ University of Cincinnati, Cincinnati, Ohio, USA \\ E-mail: Julie.Morrison@uc.edu \\ Rebecca L. Rahschulte \\ Indiana University East, Lawrenceburg, Indiana, USA \\ E-mail: rrahschu@iue.edu \\ Lauren McKinley, Allison M. Maxwell \\ University of Cincinnati, Cincinnati, Ohio, USA \\ E-mail: mckinlle@mail.uc.edu, maxwelan@mail.uc.edu
}

\begin{abstract}
The research literature on evidence-based academic interventions focuses predominantly on measures of intervention effectiveness. Intervention efficiency measures, in contrast, include the dimension of time required to achieve a level of effectiveness. The purpose of this study was to review the research literature for single-case design studies that included measures of both effectiveness and efficiency for academic (i.e., reading, math, writing, and spelling) interventions in schools. The study reviewed single-case design research on academic interventions published in six dominant peer-reviewed journals in school psychology between 2003-2013: School Psychology Review, School Psychology Quarterly, Psychology in the Schools, Journal of School Psychology, Journal of Behavioral Education, and the Journal of Evidence-Based Practices for Schools. The results of this study suggest that intervention efficiency measures are largely absent from the academic intervention research. The implications of this study are that both effectiveness and efficiency measures need to be considered as they each provide a unique contribution to determining the impact of an academic intervention.
\end{abstract}

Key words: intervention efficiency, single-case designs.

\section{Introduction}

The field of school psychology has advanced from its original focus on the assessment of student deficits to its current emphasis on prevention and intervention through comprehensive service delivery aimed at the student- and systems-levels (National Association of School Psychologists, 2010; Ysseldyke et al., 2006). The pursuit of positive, measurable outcomes for students and families relies on a foundation of empirically-supported interventions implemented in school settings (Villarreal et al., 2013). Although research has identified numerous academic interventions for use with students in schools (see Shapiro, 2004; Shinn, Walker, \& Stoner, 2002), research on 
evidence-based instructional and intervention procedures in school psychology journals remains relatively scarce (Bramlett et al., 2010; Villareal et al., 2013).

The effects of academic interventions in applied settings can be investigated through the use of an internally-valid single-subject design where each participant serves as his/her own control (Kazdin, 2010; Kennedy, 2005). Single-case designs, developed to understand patterns of individual behavior in response to an independent variable (the intervention condition), are ideally suited to measure intervention effectiveness for a variety of targeted skills/behaviors (Barnett et al., 2004). When used in school settings, each student's performance during an intervention (treatment) phase is compared to the student's baseline performance prior to intervention. Multiple-baseline designs incorporate within-student and between-student comparisons through the use of an intervention implemented individually across several students (or settings, or targeted skills) with a systematically delayed introduction. Alternating-treatment designs enable the direct comparison of academic interventions on student performance. Single-case designs provide the experimental rigor needed to establish internal validity through the detailed description of the intervention condition and the precise measure of degree to which the intervention was implemented as planned (i.e., procedural integrity, treatment integrity, intervention adherence). As such, single-case design methodology is well-suited as a foundation for intervention research examining the key features of academic interventions that lead to positive outcomes for students and the effects of these interventions when they are modified to meet the demands (i.e., time resources, and materials) of the natural school environment (Hawkins, Morrison \& Musti-Rao, 2008).

\section{Problem of Research}

Despite the critical need to establish a body of intervention research with empirical support either through scholarly journals or a recognized expert-reviewed database (Hoagwood \& Johnson, 2003; Kratochwill \& Shernoff, 2004), there has been a well-documented lack of intervention research studies in the top school psychology journals (Bramlett et al., 2010, Harrison, 2000; Kratochwill \& Stoiber, 2000; Robinson, Skinner, \& Brown, 1998; Seethaler \& Fuchs, 2005; Shriver \& Watson, 2005; Strein, Cramer, \& Lawser, 2003; Villarreal et al., 2013). For example, in their review of articles published by the four major school psychology journals (i.e., Journal of School Psychology, Psychology in the Schools, School Psychology Quarterly, and School Psychology Review) over the 11-year period from 1995 to 2005, Bramlett and associates (2010) found only 16 articles focused on reading interventions, 10 articles examined math interventions, and only one study explored a writing intervention. Of these, single-case designs were used in $11(69 \%)$ of the reading intervention articles, 3 (30\%) of the math intervention articles, and the 1 writing intervention article. Likewise, Bliss, Skinner, Hautau, and Carroll (2008) reviewed articles published in the same four major school psychology journals from 2000-2005 and identified 42 (4.5\% of the 929 studies reviewed) intervention studies that used single-case designs for academic and social/behavioral interventions.

In the most recent review of intervention research articles published in six school psychology journals (i.e., Journal of Applied School Psychology, Journal of School Psychology, Psychology in the Schools, School Psychology International, School Psychology Quarterly, and School Psychology Review) from 2005 to 2009, Villarreal and associates (2013) found that the percentage of intervention studies was higher (9.3\%) than had been previous reported in studies that focused only on the top four school psychology journals. Among the intervention research articles, $29.5 \%$ of the studies employed a single-case design methodology. The current study will extend the previous research by examining the use of single-case designs in the intervention research published in six journals relevant to school psychology with attention to the use of both effectiveness and efficiency outcome measures.

\section{Research Focus}

The goal of intervention research studies is to establish confidence that (a) within the context of the study the intervention caused the desired change in behavior, (b) the intervention or 
a similar intervention could have a similar effect across students, settings, time, and target skills/ behaviors, and (c) the intervention is practical, allowing others to implement it with success across contexts (Skinner \& Skinner, 2007). Given the goal of intervention research, intervention researchers have argued that intervention effectiveness is not sufficient for understanding the impact of an intervention due to important practical considerations relevant in schools (i.e., accountability for instructional time, resource allocation) (Cates, Burns, \& Joseph, 2010; Skinner, 2008). As such, intervention efficiency, the amount of change over baseline performance as well as an evaluation of the instructional time (i.e., number of minutes) required to bring about that change, needs to be reported along with intervention effectiveness (Cates et al., 2003; Skinner, 2008; Skinner et al., 1997; Skinner, Belfiore, \& Watson, 1995).

To illustrate, in a study comparing the effects of the Detect, Practice, and Repair (DPR) intervention package versus traditional Cover, Copy, and Compare (CCC) procedures to increase multiplication math fact accuracy (i.e., number and percentage of math facts correct) and fluency (i.e., number of math facts correct per 2 minutes) among four Grade 4 students, both the CCC intervention and the DPR intervention were effective at bringing about changes in math fact fluency and math fact accuracy relative to baseline performance (Rahschulte et al., 2014). DPR trend estimation lines were steeper than CCC trend estimation lines for all students for both math fact fluency and math fact accuracy, suggesting that the DPR intervention package was more effective than CCC procedures at bringing about changes in math fact fluency and math fact accuracy using an alternating treatments design with a modified control condition. In comparing the intervention efficiency of CCC versus DPR, the comparison of learning rates indicated that DPR was more efficient than CCC for math fact fluency for three of the four student participants, whereas CCC was more efficient than DPR for math fact accuracy.

Intervention efficiency is critically important for research and practice. Focusing exclusively on intervention effectiveness in research could yield misleading results (Skinner, 2008). For practitioners in school settings, intervention selection necessarily involves the consideration of interventions procedures that will likely produce the greatest academic growth in the shortest amount of time. Intervention effectiveness and efficiency both need to be reported in the intervention research so that researchers and practitioners can make sound decision regarding the impact of an intervention (Skinner, 2008).

The current study will extend the previous research by exploring the inclusion of intervention effectiveness and efficiency outcomes in the academic intervention research in six journals relevant to school psychology. In their review of the four major school psychology journals from 1995 to 2005, Bramlett and associates (2010) identified only two studies that directly examined the length of each intervention session when determining intervention success.

\section{Methodology of Research}

\section{General Background of Research}

Single-case designs are commonly used to measure internal validity in intervention research. Multiple-baseline designs, alternating treatment designs and $A B A B$ designs provide evidence regarding the effect of the intervention (independent variable) on the target variable (dependent variable) while controlling for extraneous variables. Although the effect of the intervention on the target variable is typically presented in terms of its effectiveness, the efficiency of the intervention is an important variable that is often overlooked. The purpose of this study was to review the research literature for single-case design studies that included measures of both effectiveness and efficiency for academic (i.e., reading, math, writing, and spelling) interventions in schools.

\section{Sample}

For the purposes of the current review, a literature search was conducted using the PsychInfo and ERIC databases. The search was limited to peer-reviewed, empirical research studies published 
between 2003 and 2013 in order to extend and expand the literature search conducted by Bramlett et al., (2010). As in the Bramlett et al. (2010) study, four school psychology journals were reviewed: Psychology in the Schools (PITS), School Psychology Quarterly (SPQ), School Psychology Review (SPR), and The Journal of School Psychology (JSP). The Journal of Behavioral Education (JOBE) and the Journal of Evidence-Based Practices for Schools (JEBP) were also reviewed in the current study. Given that the focus of this study was on the use of effectiveness and efficiency measures for academic interventions (i.e., reading, writing, or math), articles targeting behavioral variables were not included.

Only studies of school-age children in general or special education programs were included in this review. All of the studies were required to (a) include an internally-valid single-case design, (b) report observational data, (c) provide checks for reliability, and (d) take place in a school setting.

A total of 2,739 references were identified for articles published among the six journals between 2003-2013. After removing articles that did not involve an empirical research study of an academic intervention, 151 studies remained. The abstracts were reviewed in order to identify studies meeting the selection criteria, and if that information was insufficient, the full article was reviewed. At this point, an additional 67 studies were deleted due to a lack of fit with the inclusion criteria. In the end, a total of 83 studies were identified that met all inclusion criteria (a complete list of references is available upon request from Julie Q. Morrison).

\section{Instrument and Rating Procedures}

Using the university library's e-journal database, four coders (one school psychology faculty member, one psychology faculty member, and two school psychology graduate students) were trained to locate, retrieve, and code the articles identified in the selected school psychology journals. The coding conventions were developed jointly during a one hour face-to-face meeting. The resulting coding protocol was comprised of 11 key variables, which included: journal name, publication year, citation, participant (e.g., gender, age, and disability), setting, number of students targeted, length of intervention condition, duration of intervention per session, effectiveness variable, efficiency variable, and single-case research design. The primary variables of interest were the frequency of articles with (a) results reported without reference to the amount of time required to yield the outcome (effectiveness variable), and (b) results reported as a function of the amount of time required to implement the intervention (efficiency variable).

In coding the efficiency variable, a distinction was made between an efficiency variable (i.e., learning rate) and an effectiveness variable reported as a rate of improvement. Intervention efficiency is computed by dividing the number of units learned by the amount of instructional time (i.e., number of minutes) (Cates, Burns \& Joseph, 2010; Skinner, Belfiore \& Watson, 1995). In contrast, a rate of improvement is calculated by dividing the number of units learned by the amount of time lapsed (i.e., weeks of school). Whereas a rate of improvement provides useful information regarding the effectiveness of an intervention as evident in weekly gains in student skill fluency, to be considered an efficiency variable, the gains in student skill fluency need to be anchored by the amount of instructional/intervention time.

To established inter-rater reliability, one half of the articles were randomly selected for review by a second coder. The two researchers in this study also served as a second coder for any of the articles identified as having an efficiency variable in the first review that were not selected for inclusion in the second round of reviews. As such, $56.5 \%$ of the articles were reviewed by an independent second coder. The second review focused on the primary variables of interest: (a) evidence of an effectiveness variable, and (b) evidence of an efficiency variable. The percentage of inter-rater reliability was calculated by dividing the number of agreements by the number of agreements and disagreements and multiplying by 100 . Inter-rater reliability for the effectiveness variable(s) was $100 \%$. Inter-rater reliability for the efficiency variable was $89.6 \%$. Any questions, concerns, or disagreements were resolved by the primary author in consultation with the secondary author. 
Descriptive statistics were used to summarize and analyze the data gathered with the coding protocol. Specifically, frequency counts, cross-tabulations, and percentages were calculated in the analysis of publication outcomes by year and publication outcomes by journal.

\section{Results of Research}

\section{Academic Intervention Articles by Journal}

Over the 11-year period, 2,739 articles were published in the six journals relevant to school psychology in the years 2003 through 2013 (See Table 1). Of these articles, only $3.1 \%$ overall focused on the effectiveness of an academic intervention using a single-case design. The greatest number of articles examining the impact of academic interventions using single-case designs were found in the two journals not included in the previous studies of the intervention research literature (Bliss et al., 2008; Bramlett et al., 2010; Villarreal et al., 2013), the Journal of Evidence Based Practices in Schools and the Journal of Behavioral Education. The Journal of Evidence Based Practices in Schools published 17 articles (14.2\% of the articles published) dedicated to academic interventions using single-case designs. The 17 articles explored academic interventions targeting reading/early literacy (10), math (5), spelling/vocabulary (1), and writing (1). The Journal of Behavioral Education published 43 articles (18.4\% of the articles published) focused on academic interventions using single-case designs. The 43 articles examined academic interventions targeting reading/early literacy (25), math (9), spelling (4), and writing (5). Among the four major school psychology journals, Psychology in the Schools had the highest frequency of articles examining academic interventions using single-case designs with 14 articles, but this only represented $1.6 \%$ of the total number of articles published by Psychology in the Schools. The 14 articles focused on academic interventions targeting reading/early literacy (9) and math (5). The remaining three school psychology journals published very few articles investigating the effectiveness of academic interventions using singlecase designs: Journal of School Psychology (1 reading intervention article, representing 0.1\%), School Psychology Quarterly (1 writing intervention article, representing 0.3\%), School Psychology Review ( 9 articles: 7 reading, 2 math, representing 2.0\%).

Table 1. Frequency and percentage of articles examining academic intervention effectiveness using single-case designs in journals relevant to school psychology, 2003-2013.

\begin{tabular}{ccc}
\hline Journal Name & $\begin{array}{c}\text { Total Number of } \\
\text { Articles Published } \\
\mathbf{2 0 0 3 - 2 0 1 3}\end{array}$ & $\begin{array}{c}\text { Number (and \%) of } \\
\text { Academic Intervention } \\
\text { Articles using } \\
\text { Case Designs }\end{array}$ \\
\hline Journal of Evidence Based Practices in Schools & 120 & $17(14.2 \%)$ \\
Journal of Behavioral Education & 234 & $43(18.4 \%)$ \\
Journal of School Psychology & 738 & $1(0.1 \%)$ \\
Psychology in the Schools & 894 & $14(1.6 \%)$ \\
School Psychology Quarterly & 309 & $1(0.3 \%)$ \\
School Psychology Review & 444 & $9(2.0 \%)$ \\
Total & 2,739 & $85(3.1 \%)$ \\
\hline
\end{tabular}


Julie Q. MORRISON, Rebecca L. RAHSCHULTE, Lauren MCKINLEY, Allison M. MAXWELL. Examining intervention effectiveness and efficiency outcomes in single-case design studies

\section{Effectiveness and Efficiency Variables by Journal}

Of the 85 empirical research articles examining academic interventions using a single-case design, 85 (100\%) featured an effectiveness variable(s), but only 14 (16.5\%) included an efficiency variable. Efficiency variables were most frequently identified in the Journal of Behavioral Education (6), followed by Psychology in the Schools (4), and School Psychology Review (3) (See Figure 1). The Journal of Evidence Based Practices had only one article that included an efficiency variables and the Journal of School Psychology and School Psychology Quarterly did not have any studies published with efficiency variables reported.

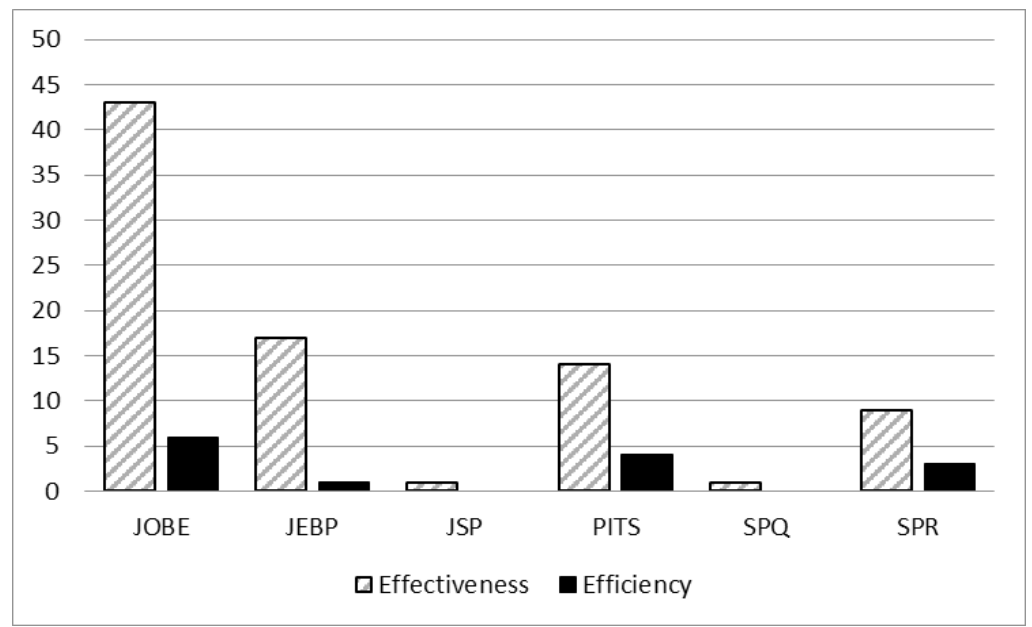

Figure 1. Frequency of studies reporting academic effectiveness and efficiency outcomes by journal, 2003-2013.

\section{Effectiveness and Efficiency Variables by Publication Year}

The publication of research articles examining the effectiveness of academic interventions using a single-case design was variable across the 11-year period from 2003 through 2013. Studies investigating the effectiveness of academic interventions were published most frequently in 2006 and 2010. There has been a steady downward trend in the frequency of published effectiveness studies from 2010 to 2013 (See Figure 2). With the exception of 2007 in which four studies included an efficiency variable, no more than two articles featured an efficiency variable in a given year.

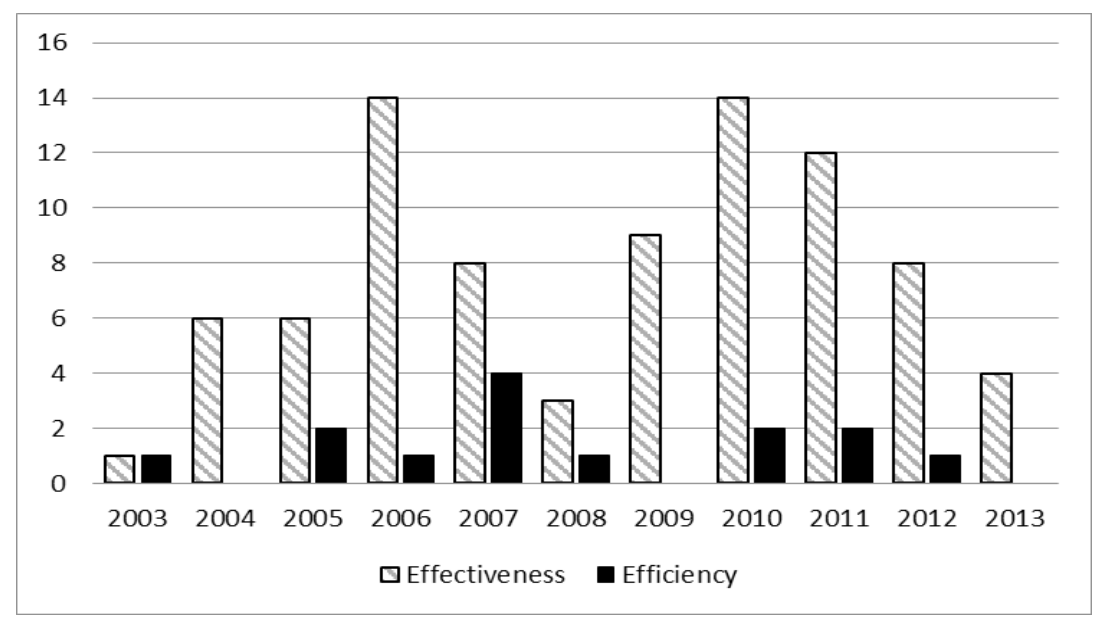

Figure 2. Frequency of studies reporting academic effectiveness and efficiency outcomes by publication year. 


\section{Discussion}

The aim of the present literature review was to update and extend the previous studies of the intervention research literature found in school psychology journals, with a particular focus on the presence of academic effectiveness and efficiency outcome measures. Our literature review yielded some important information regarding the publication trends over the 11-year period from 2003 through 2013. The review demonstrated that two journals relevant to school psychology, but not considered to be among the top four school psychology journals, published the greatest number of articles dedicated to academic intervention research studies using single-case designs. The journals relevant to school psychology, Journal of Behavioral Education and the Journal of Evidence Based Practices in Schools, were not included in previous studies of the intervention research (Bliss et al., 2008; Bramlett et al., 2010; Villarreal et al., 2013), and yet clearly make a much needed contribution to advancing the body of intervention research with empirical support.

Consistent with previous findings, an examination of the top four school psychology journals (and collectively all six journals in this literature review) yielded relatively few articles describing the results of academic interventions using a single-case design. This trend persists over an 11year period, despite long-standing calls to address the scarcity of intervention research within the school psychology literature (Bramlett et al., 2010, Harrison, 2000; Hoagwood \& Johnson, 2003; Robinson, Skinner \& Brown, 1998; Seethaler \& Fuchs, 2005; Shriver \& Watson, 2005; Strein, Cramer \& Lawser, 2003; Villarreal et al., 2013). In the present study, 3.1\% of the articles published in the six journals relevant to school psychology focused on academic interventions using a single-case design. This figure is similar to the results obtained by Bliss and associates (2008), who reported $4.5 \%$ of the articles published in the four major school psychology journals from 2000 to 2005 described intervention studies that used single-case designs for academic and social/behavioral interventions. Likewise, Villarreal and associates (2013) found 9.3\% of the articles published in six school psychology journals from 2005 to 2009, were dedicated to academic and social/behavioral intervention research, with slightly less than a third of these articles employing a single-case design. The scarcity of academic intervention research available to school psychologists in the most prominent journals in the field is troubling given the reliance of practitioners on the empirical studies to make informed decisions regarding the use of evidence-based interventions. This finding also has implications for researchers who may forgo scholarship dedicated to advancing intervention research in light of the low publication rates.

In the present study, the frequency of published articles examining the effectiveness of academic interventions using a single-case design was variable across the 11-year period from 2003 through 2013 with greater frequency in 2006 and 2010 and a steady downward trend from 2010 to 2013. This result is consistent with and extends the findings of the literature review conducted by Villarreal and associates (2013), who reported a significant downward trend in single-case intervention research published in six school psychology journals from 2005 to 2009 . This variability and general decline in the frequency of single-case design intervention research is surprising given the emphasis on using single-case design research within a Response to Intervention framework for meeting students' needs (Jimerson, Burns, \& VanDerHeyden, 2007; Riley-Tillman \& Burns, 2009) and for evaluating evidence-based practices and professional accountability among school psychologists (Morrison, 2013; Morrison, Graden, \& Barnett, 2009).

Despite calls from intervention researchers to examine impact in terms of effectiveness and the amount of instruction/intervention time to achieve effectiveness (efficiency), the results of this study indicate that efficiency variables remain largely absent in the academic intervention research, with rarely more than two efficiency studies published in a given year. In the present review of the literature, 14 articles were identified that included a calculation of efficiency. The literature review conducted by Bramlett et al. (2010) identified only two articles that included the amount of instructional time needed to generate the effect obtained among publications from 1995 to 2005. This slight increase is negligible given the larger proportion of intervention effectiveness studies that did not include an efficiency variable. Furthermore, this finding was particularly disconcerting given that the amount of instructional/intervention time was reported in minutes for slightly more 
than half (47, or $55.3 \%$ ) of the 85 articles included in the present review and presumably a learning rate could have been calculated with relative ease.

Several limitations of the present study are worthy of consideration when examining its findings. Although the journals examined represent major publication sources in school psychology, they do not represent all of the possible publication outlets in school psychology, which would also include School Psychology International and the Journal of Applied School Psychology. By including two journals relevant to school psychology that are more inclined to publish research with a behavioral theoretical orientation, the authors of this study sought to maximize the likelihood of finding academic intervention research using single-case designs. A different selection of journals may have yielded a markedly different sample of articles. It is also possible, as Villarreal et al. (2013) point out, many school psychology researchers may publish their intervention studies in journals related to their particular research focus (e.g., early childhood intervention, autism). Future research should explore the frequency of intervention research published by school psychology-affiliated researchers in journals not exclusively relevant to school psychology.

The body of research on empirically-validated academic interventions was restricted in this study by focusing only on studies that used single-subject design methodology. As such, the frequency of academic research studies that included effectiveness and efficiency outcome variables may have been greater than reported in this study if other research designs were included in the literature review. Furthermore, the body of intervention research literature was further limited by focusing on interventions targeting academic skill remediation. Future research should explore the degree to which the findings of this study hold when the focus is on interventions targeting social/behavioral concerns.

\section{Conclusions}

The current demand for accountability and evidence-based practices within the field of school psychology creates an undeniable sense of urgency among for researchers and practitioners to use empirically-validated studies as a basis for intervention design and selection. The findings of this study indicate that the current status of intervention research targeting academic interventions is not as extensive as it needs to be to inform research and practice in school psychology and largely fails to consider intervention efficiency along with intervention effectiveness when evaluating the impact of the intervention. The need for more academic intervention research using single-case designs and reporting intervention effectiveness and efficiency persists as a critical problem within school psychology.

\section{References}

Barnett, D. W., Daly, E. J. III, Jones, K. M., \& Lentz, F. E. (2004). Response to Intervention: Empirically based special service decisions from single-case designs of increasing and decreasing intensity. The Journal of Special Education, 38 (2), 66-79.

Bliss, S. L., Skinner, C. H., Hautau, B., \& Carroll, E. E. (2008). Articles published in four school psychology journals from 2000 to 2005: An analysis of experimental/intervention research. Psychology in the Schools, 45 (6), 483-495. DOI: 10.1002/pits.20318.

Bramlett, R., Cates, G. L., Savina, E., \& Lauinger, B. (2010). Assessing effectiveness and efficiency of academic interventions in school psychology journals: 1995-2005. Psychology in the Schools, 47 (2), 114-125. DOI: $10.1002 /$ pits.20457.

Cates, G. L., Burns, M. K., \& Joseph, L. M. (2010). Introduction to the special issue: Instructional efficiency and the impact on learning and data-based decision making. Psychology in the Schools, 47 (2), 111-113. DOI: $10.1002 /$ pits.20456.

Cates, G. L., Skinner, C. H., Watson, T. W., Meadows, T. J, Weaver, A., \& Jackson, B. (2003). Instructional effectiveness and instructional efficiency as considerations for data-based decision making: An evaluation of interspersing procedures. School Psychology Review, 32 (4), 601-616. 
Harrison, P. L. (2000). School Psychology Review: Ending the $20^{\text {th }}$ century and looking ahead to the future. School Psychology Review, 29 (4), 473-482.

Hawkins, R. O., Morrison, J. Q., \& Musti-Rao, S. (2008). Treatment integrity for academic interventions in real world settings. School Psychology Forum: Research in Practice, 2 (3), 1-15.

Hoagwood, K., \& Johnson, J. (2003). School psychology: A public health framework: From evidence-based practices to evidence-based policies. Journal of School Psychology, 41 (1), 3-21.

Kazdin, A. E. (2010). Single-case research designs: Methods for clinical and applied settings (2 ${ }^{\text {nd }}$ Edition). New York: Oxford University Press.

Kennedy, C. H. (2005). Single case designs for use in educational research. Boston, MA: Pearson Education, Inc.

Kratochwill, T. R., \& Shernoff, E. S. (2004). Evidence-based practice: Promoting evidence-based intervention in school psychology. School Psychology Review, 33 (1), 34-48.

Kratochwill, T. R., \& Stoiber, K. C. (2000). Uncovering critical research agendas for school psychology: Conceptual dimensions and future directions. School Psychology Review, 29 (4), 591-603.

Jimerson, S. R., Burns, M. K., \& VanDerHeyden, A. M. (2007). Handbook of response to intervention: The science and practice of assessment and intervention. New York, NY: Springer.

Morrison, J. Q. (2013). Performance evaluation and accountability for school psychologists: Challenges and opportunities. Psychology in the Schools, 50 (3), 314-324. DOI: 10.1002/ pits.21670.

Morrison, J. Q., Graden, J. L., \& Barnett, D. W. (2009). Steps to evaluating a state-wide internship program: Model, trainee, and student outcomes. Psychology in the Schools, 46 (10), 989-1005. DOI: 10.1002/pits.

Riley-Tillman, C. T., \& Burns, M. K. (2009). Evaluating educational interventions: Single-case design for measuring response to intervention. New York: Guildford Press.

National Association of School Psychologists (2010). Model for Comprehensive and Integrated School Psychological Services. Baltimore. MD: Author.

Rahschulte, R. L., Morrison, J. Q., Hawkins, R. O., \& Bauer, A. M. (2014). An examination of the effectiveness and efficiency of Detect, Practice, and Repair versus traditional Cover, Copy, and Compare procedures: A component analysis (Unpublished doctoral dissertation). Cincinnati, OH: University of Cincinnati.

Robinson, S. L., Skinner, C. H., \& Brown, C. S. (1998). An analysis of articles appearing in school psychology journals from 1985-1994. Proven Practice: Prevention and Remediation Solutions for Schools, 1 (1), 28-33.

Seethaler, P. M., \& Fuchs, L. S. (2005). A drop in the bucket: Randomized controlled trials testing reading and math interventions. Learning Disabilities Research and Practice, 20 (2), 98-102. DOI: 10.1111/j.15405826.2005.00125.x.

Shapiro, E. S. (2004). Academic skills problems: Direct assessment and intervention ( $3^{\text {rd }}$ ed.). New York: Guilford.

Shinn, M. R., Walker, H. M., \& Stoner, G (Eds.) (2002). Interventions for academic and behavior problems II: Preventive and remedial approaches. Washington DC: National Association of School Psychologists.

Shriver, M. D., \& Watson, T. S. (2005). Bridging the great divide: Linking research to practice in scholarly publications. Journal of Evidence Based Practices for Schools, 6 (1), 5-18.

Skinner, C. H. (2008). Theoretical and applied implications of precisely measuring learning rate. School Psychology Review, 37 (3), 309-314.

Skinner, C. H., Belfiore, P. J., Mace, H. W., Williams, S., \& Johns, G. A. (1997). Alternating response topography to increase response efficiency and learning rates. School Psychology Quarterly, 12 (1), 54-64.

Skinner, C. H., Belfiore, P. J., \& Watson, T. S. (1995). Assessing the relative effects of interventions in students with mild disabilities: Assessing instructional time. Assessment in Rehabilitation Exceptionality, 2, 207-220.

Skinner, C. H., \& Skinner, A. L. (2007). Establishing an evidence base for a classroom management procedure with a series of studies: Evaluating the color wheel. Journal of Evidence Based Practices for Schools, 8, 88-101.

Strein, W., Cramer, K., \& Lawser, M. (2003). School psychology research and scholarship. School Psychology International, 24 (4), 421-436. 
Villarreal, V., Gonzalez, J. E., McCormick, A. S., Simek, A., \& Yoon, H. (2013). Articles published in six school psychology journals from 2005-2009: Where's the intervention research? Psychology in the Schools, 50 (5), 500-518. DOI: $10.1002 /$ pits.21687.

Ysseldyke, J., Morrison, D., Burns, M., Ortiz, S., Dawson, P., Rosenfield, S., Kelley, B., .. . Telzrow, C. (2006). School psychology: A blueprint for training and practice III. Bethesda, MD: National Association of School Psychologists.

\section{Appendix}

\section{CODING PROTOCOL}

The Coding Protocol was created using a Microsoft Excel with the following variables:

\begin{tabular}{|c|c|c|}
\hline Variable & Description & Coding \\
\hline Coder & $\begin{array}{l}\text { This variable identifies the } \\
\text { coder }\end{array}$ & Enter the coder's initials \\
\hline Source & $\begin{array}{l}\text { This variable identifies the } \\
\text { journal }\end{array}$ & $\begin{array}{l}\text { Enter the journal's abbreviation } \\
\text { JEBP = Journal of Evidence Based Practice in Schools } \\
\text { JOBE = Journal of Behavioral Education } \\
\text { JSP = Journal of School Psychology } \\
\text { PITS = Psychology in the Schools } \\
\text { SPQ = School Psychology Quarterly } \\
\text { SPR = School Psychology Review }\end{array}$ \\
\hline Year & $\begin{array}{l}\text { This variable identifies the } \\
\text { publication year }\end{array}$ & $\begin{array}{l}\text { Enter the four-digit year. If the on-line publication year preceeds the } \\
\text { hard copy publication year, enter the hard copy publication year. }\end{array}$ \\
\hline Citation & $\begin{array}{l}\text { This variable uniquely } \\
\text { identifies the article }\end{array}$ & Enter authors last names and publication year \\
\hline Participants & $\begin{array}{l}\text { This variable describes the } \\
\text { participants of the study }\end{array}$ & $\begin{array}{l}\text { Enter grade, age, gender, race, general ed/special ed status, and } \\
\text { disability (if applicable) for each participant }\end{array}$ \\
\hline Setting & $\begin{array}{l}\text { This variable describes } \\
\text { the location in which } \\
\text { the intervention was } \\
\text { implemented }\end{array}$ & $\begin{array}{l}\text { Enter description provided by the authors of the study. } \\
\text { Examples include: classroom or separate room near the classroom }\end{array}$ \\
\hline $\mathrm{N}$ & $\begin{array}{l}\text { This variable identifies } \\
\text { the number of student } \\
\text { participants in the study }\end{array}$ & $\begin{array}{l}\text { Enter the number of students who participated in the study. If the } \\
\text { study used peers as interventionist (e.g., peer tutoring), record only } \\
\text { the number of target students who received support. }\end{array}$ \\
\hline Length & $\begin{array}{l}\text { This variable identifies } \\
\text { the length of intervention } \\
\text { condition }\end{array}$ & $\begin{array}{l}\text { Enter description provided by the authors of the study regarding the } \\
\text { number of days or weeks of intervention. If multiple interventions } \\
\text { were implemented or modifications were made to the intervention } \\
\text { package, record the total length of the intervention condition(s). }\end{array}$ \\
\hline Duration & $\begin{array}{l}\text { This variable identifies the } \\
\text { duration of the planned } \\
\text { intervention session }\end{array}$ & $\begin{array}{l}\text { Enter the duration of each intervention session in minutes. This is } \\
\text { typically reported as a range. Example: } 10-12 \text { minute session }\end{array}$ \\
\hline Design & $\begin{array}{l}\text { This variable identifies the } \\
\text { single-case design }\end{array}$ & $\begin{array}{l}\text { Enter the code for the design as: } \\
1=\text { Multiple-baseline design } \\
2=\text { Alternating treatment design/Multielement design } \\
3=\text { ABA or ABAB design } \\
4=\text { Multiple probe across problem set } \\
5=\text { Other (Specify) }\end{array}$ \\
\hline Effectiveness & $\begin{array}{l}\text { This variable identifies the } \\
\text { effectiveness variable(s) }\end{array}$ & $\begin{array}{l}\text { Enter description provided by the authors of the study regarding } \\
\text { their dependent variable(s) }\end{array}$ \\
\hline
\end{tabular}


Julie Q. MORRISON, Rebecca L. RAHSCHULTE, Lauren MCKINLEY, Allison M. MAXWELL. Examining intervention effectiveness and efficiency outcomes in single-case design studies

Efficiency This variables identifies the efficiency variable
Enter description provided by the authors of the study regarding their measure of efficiency - intervention effect per instructional/ intervention time in minutes. Learning rates, rates of improvement, and student growth per week are not efficiency measures if they are based on the passage of time (i.e., days, weeks) and not anchored to instructional/intervention time.
Advised by Stanislava Yordanova Stoyanova, South-West University "Neofit Rilski", Bulgaria
ISSN 2029-8587

PROBLEMS

OF PSYCHOLOGY

IN THE $21^{\text {st }}$ CENTURY

Vol. 8, No. 2, 2014

171

Received: August 26, 2014

Accepted: November 30, 2014

Julie Q. Morrison Ph.D., Associate Professor, University of Cincinnati, P.O. Box 210068, Cincinnati, $\mathrm{OH}$ 45221-0068, USA.

E-mail: Julie.Morrison@uc.edu

Rebecca L. Rahschulte

Ph.D., Adjunct Professor, Indiana University East, Lawrenceburg, 500 Industrial Drive, Lawrenceburg, IN 47052, USA.

E-mail: rrahschu@iue.edu

Lauren McKinley Ed.S., Graduate Student, University of Cincinnati, P.O. Box 210068, Cincinnati, $\mathrm{OH}$ 45221-0068, USA.

E-mail: mckinlle@mail.uc.edu

Allison M. Maxwell M.Ed., Graduate Student, University of Cincinnati, P.O. Box 210068, Cincinnati, OH 45221-0068, USA.

E-mail: maxwelan@mail.uc.edu 